Article

\title{
Olive Leaves Extract from Algerian Oleaster (Olea europaea var. sylvestris) on Microbiological Safety and Shelf-life Stability of Raw Halal Minced Beef during Display
}

\author{
Djamel Djenane $^{1, * \mathbb{C}}$, Diego Gómez ${ }^{2}$, Javier Yangüela ${ }^{2}$, Pedro Roncalés ${ }^{2}$ and Agustín Ariño ${ }^{2} \mathbb{D}$ \\ 1 Laboratoire de Qualité et Sécurité des Aliments (LQSA), Faculté des Sciences Biologiques et des Sciences \\ Agronomiques, Université Mouloud MAMMERI, B.P. 17, 15000 Tizi-Ouzou, Algeria \\ 2 Instituto Agroalimentario de Aragón-IA2 (Universidad de Zaragoza-CITA), Facultad de Veterinaria, \\ C/Miguel Servet 177, 50013 Zaragoza, Spain; dgl.15@hotmail.com (D.G.); jyangu@unizar.es (J.Y.); \\ roncales@unizar.es (P.R.); aarino@unizar.es (A.A.) \\ * Correspondence: djenane6@yahoo.es; Tel.: +213-779-001-384; Fax: +213-262-168-19
}

Received: 16 November 2018; Accepted: 21 December 2018; Published: 26 December 2018

\begin{abstract}
Oleaster (wild olive tree) by-products represent a renewable and low-cost source of biopolyphenols. Leaf extracts (sylv.OLE) of Algerian oleaster, locally called $a^{\prime}$ hachad (Olea europaea subsp. europaea var. sylvestris), were applied at 1 and $5 \%(\mathrm{v} / \mathrm{w})$ to raw Halal minced beef (HMB) in order to test its safety and shelf-life prolongation during retail/display. The total phenolic compound content in the extract was $198.7 \pm 3.6 \mathrm{mg}$ gallic acid equivalent. Ten compounds were identified in the sylv.OLE by High Performance Liquid Chromatography / Diode Array Detector (HPLC/DAD), of which oleuropein was the most abundant $(43.25 \%)$. Samples treated with 5\% sylv.OLE had significantly higher antimicrobial and antioxidant effects than those treated with $1 \%$ extract $(p<0.05)$. The addition of sylv.OLE reduced psychrotrophic counts as well as the level of pathogens (Salmonella enterica ser. Enteritidis and Shiga toxin-producing Escherichia coli O157:H7). A thiobarbituric acid reactive substance (TBARS) value of $2.42 \pm 0.11$ was reached throughout six days of retail/display in control samples, while the addition of $5 \%$ sylv.OLE reduced TBARS value by $58 \%(p<0.05)$. The presence of sylv.OLE at the tested concentrations did not negatively influence the overall acceptability and bitterness of HMB.
\end{abstract}

Keywords: wild olive tree; by-products; leaf extracts; High Performance Liquid Chromatography/ Diode Array Detector (HPLC/DAD); Halal minced beef; retail/display; safety; Escherichia coli O157:H7; Salmonella enterica ser. Enteritidis; shelf-life

\section{Introduction}

In Spain, the real importance of Halal markets is high, and the global demand for meat slaughtered for Muslim consumption is expected to grow even faster. Halal minced beef (HMB) is widely consumed in many forms because of its popularity among immigrants, and for its attractive price. However, if conditions are favorable for microbial growth, minced beef can present a health risk to consumers. Pathogenic shiga toxin-producing Escherichia coli (STEC) O157:H7 and Salmonella enterica ser. Enteritidis have been reported as the major public health concerns, and have been the cause of a series of outbreaks in Europe linked to eating undercooked minced beef sold from fast-food restaurant chains and sometimes directly sold from local butchers [1].

The olive tree (Olea europaea, Oleaceae) is one of the plants mentioned in the Holy Quran (By the Fig and the Olive ${ }^{\text {(verse1) }}$, by Mount Sinai ${ }^{\text {(verse2) }}$, and by this City of Security (verse3): Coran, Surah 
95/At'tin), and provided huge economic assets. The excellent properties of olive biophenols are a consequence of their function in the olive tree. Phenolic compounds are often involved in plant-based defense mechanisms against predation by insects, herbivores, and against multiple microbial infections. They are also responsible for the sensory properties of plants such as color, taste, and sometimes smell. In herbal medicine, the effect of olive leaves is attributed in whole, or in part, to their phenolic compounds [2]. These substances have biological activities that make them beneficial to human health. Many studies indicate that polyphenols can reduce the risk of a number of pathologies, especially those related to aging and oxidative damage (cancer, cardiovascular, or neurodegenerative diseases) $[3,4]$. These scientific findings have already led to approved health claims. These substances can also be used to improve the safety, shelf-life, and to develop functional foods [5]. Conditions in the Algerian region favor the growth of wild olive trees, which have provided Algerian people with dietary and economic benefits since ancient years. The "Kabylie" region is the most productive Algerian region of oleaster olive oil. Once the oil is extracted, the waste is often stored and released into the wild. However, by-products of oleaster leaves are a good source of added value biophenols that can be used in the food industry [6-8]. In this context, the recovery of waste from the olive industry seems to be an interesting market since it would respond to a current environmental problem $[9,10]$. Wild olive trees (oleaster) are distinguished from cultivated ones by a long juvenile period and a greater capacity for survival in difficult environments. Oleaster contains small fruits characterized by a slower mesocarp/stone ratio, it gives much lower yields in oils compared to cultivated olive trees. Several works on the biological activity of olive leaves have been carried out $[5,6,11]$. These effects are mainly attributed to the presence of main polyphenols in olive leaves such as secoiridoids (ligstroside, oleuropein), verbascoside, phenolic alcohols (hydroxytyrosol, tyrosol), and flavonoids (luteolin-7-glucoside, luteolin, rutin, and apigenin-7-glucoside). The majority of studies to date regarding the biological effects of olive leaves in the food field are usually in vitro studies [12,13].

In order to promote local products, Algerian wild olive leave extracts were used as source of natural biophenolic compounds for the enrichment of HMB commonly used for various practical meals by the Muslim community, particularly those living in Spain. Supplementation was performed at two different levels ( 1 and $5 \%, \mathrm{v} / \mathrm{w}$ ) on microbiological safety and shelf-life during retail/display.

\section{Materials and Methods}

\subsection{Olive Leaves Material}

Fresh leaves from wild olive trees (locally called: a'hachad: Olea europaea subsp. europaea var. sylvestris) were collected after fruit harvesting during the period of February 2010-2012 in Ghoumrassa (Bordj-Ménaïel city: Kabylie, Algeria), from trees that have never been treated with phytosanitary products. The collected leaves were not the residues resulting from olive tree pruning, but the leaves obtained after the washing and cleaning of the olives at their entrance into the oil mill. For this, samples of leaves were collected from different parts of the trees in the same locality. The quantity of these oleaster by-products was estimated in Algeria at $\approx 5 \%$ of the weight of olives. Harvested leaves were immediately transferred to the laboratory, rinsed thoroughly with sterile distilled water to remove dust and contaminating material, and air dried at room temperature $\left(\sim 28^{\circ} \mathrm{C}\right)$ during two months. After drying, the dried leaves were immediately vacuum packed, and stored in dark at $1{ }^{\circ} \mathrm{C} \pm 0.5^{\circ} \mathrm{C}$ until their use in the extraction processes during the experimental period mentioned above.

\subsection{Preparation of Powder and Olive Leaves Extract}

The packaged dried olive leaves were ground into powder (size of $\sim 0.1 \mathrm{~mm}$ ). The extraction was carried out by maceration of the olive leaf powder in the methanol/water $(80: 20, \mathrm{v} / \mathrm{v})$, and the mixture was kept under agitation for $24 \mathrm{~h}$. Insoluble material was removed by centrifugation at $15,000 \times g$ for $40 \mathrm{~min}$. Subsequently, the clear supernatant was obtained after evaporation of the solvent by a rotary evaporator under vacuum at $40^{\circ} \mathrm{C}$. Then the supernatant was filtered $(0.45 \mu \mathrm{m})$ to obtain the olive 
leaves extract, which was stored in light protected glass vials at $-20^{\circ} \mathrm{C}$ until further High Performance Liquid Chromatography (HPLC) analysis and use.

\subsection{Estimation of the Total Phenolic Compounds in the Olive Leaves Extract}

Total phenolic compounds (TPC) in the sylv.OLE (extract from leaves of Algerian oleaster) were determined according to the Folin-Ciocalteu method [14] with some modifications. Two and a half milliliter $(2.5 \mathrm{~mL}$ ) portions of the Folin-Ciocalteu reagent (Sigma-Aldrich, Barcelona, Spain) were added to aliquots of $0.5 \mathrm{~mL}$ of extract, and incubated in the dark for $10 \mathrm{~min}$ (reaction). Then, $2 \mathrm{~mL}$ of a sodium carbonate solution $(75 \mathrm{~g} / \mathrm{L})$ was added to the mixture, and the reaction was kept in the dark for $45 \mathrm{~min}$. The assay tubes were vortexed and incubated at $45^{\circ} \mathrm{C}$ for $10 \mathrm{~min}$, and then cooled. For the blank assay, $0.5 \mathrm{~mL}$ of distilled water was used. Mixture absorbance was then read at $760 \mathrm{~nm}$ using a Jasco V-360 spectrophotometer (Jasco, Tokyo, Japan). Gallic acid was used as phenolic compound standard for the calibration curve, and TPC in sylv.OLE were expressed as milligrams of Gallic acid equivalents per gram of sample dry weight (mg GAE/g). Data were presented as the average of triplicate analyses.

\subsection{Analysis of Phenolic Compounds in sylv.OLE}

The constituents of the sylv.OLE extract were performed with an analytical High Performance Liquid Chromatography unit (Agilent Technologies 1200 series, Santa Clara, CA, USA), equipped with a diode array detector (HPLC/DAD). The stationary phase was an Atlantis®Waters dC18 column $(5 \mu \mathrm{m}, 4.6 \times 250 \mathrm{~mm})$. The elution was carried out in gradient mode using a binary solvent mixture composed of water, acidified with 5\% formic acid (solvent A), and 95\% methanol (solvent B) with a total analysis time of 50 minutes. The column was re-equilibrated for 4 min between each analysis. The flow rate of the mobile phase was $1 \mathrm{~mL} / \mathrm{min}$, and the injection volume of the extract sample was $10 \mu \mathrm{L}$. The UV absorption spectra of the standards as well as the samples were recorded in the range of 230-400 nm. Peaks of the phenolic compound were identified by comparing their retention times with those of the standards, and checking their characteristic spectra. Quantification of phenolic compounds was done by calibration curves relative to external standards, developed by injecting different amounts of a known standard compound in the HPLC column.

\subsection{In Vitro Antioxidant Activity}

The radical-scavenging activity (RSA) was measured using the stable radical 2,2-diphenyl-1-picrylhydrazyl (DPPH•) in methanolic solution according to spectrophotometric methods described by Taoudiat et al. [15]. The percentage of DPPH• radical scavenging activity (RSA) was calculated using the following Equation:

$$
\operatorname{RSA}(\%)=\left[\left(\mathrm{Abs}_{(\mathrm{DPPH})}-\mathrm{Abs}_{\left(\text {sylv.OLE }_{)}\right)} / \mathrm{Abs}_{(\mathrm{DPPH})}\right] \times 100\right.
$$

- $\quad \operatorname{Abs}_{(\mathrm{DPPH})}=$ absorbance value at $517 \mathrm{~nm}$ of the methanolic solution of DPPH.

- $\quad A_{\text {(sylv.OLE) }}=$ absorbance value at $517 \mathrm{~nm}$ for the sylv.OLE.

The RSA was also expressed as the $\mathrm{IC}_{50}$ value $(\mu \mathrm{g} / \mathrm{mL})$; the concentration required to cause $50 \%$ of DPPH inhibition. To standardize DPPH results, the antioxidant activity index (AAI), proposed by Scherer and Godoy [16], and was calculated as follows:

$$
\mathrm{AAI}=\mathrm{DPPH} \text { concentration in reaction mixture }(\mu \mathrm{g} / \mathrm{mL}) / \mathrm{IC}_{50}(\mu \mathrm{g} / \mathrm{mL})
$$

- $\quad$ AAI $<0.5$ (poor antioxidant activity).

- $\quad 0.5<\mathrm{AAI}<1.0$ (moderate antioxidant activity).

- $\quad 1.0<\mathrm{AAI}<2.0$ (strong antioxidant activity).

- $\quad$ AAI $>2.0$ (very strong activity). 


\subsection{Application in Halal Minced Beef}

The experimental design is shown in Figure 1. Briefly, the extract was obtained from olive leaves of Algerian oleaster (sylv.OLE), and lots of Halal minced beef (HMB) samples were supplemented with 0 (control), 1, and $5 \%$ of sylv.OLE. Two lots of HMB were inoculated with pathogenic bacteria (Salmonella and E. coli) and maintained at $7{ }^{\circ} \mathrm{C}$ during display for 6 days. The sylv.OLE was chemically characterized and HMB samples were analyzed for microbial, oxidative, and sensory characteristics.
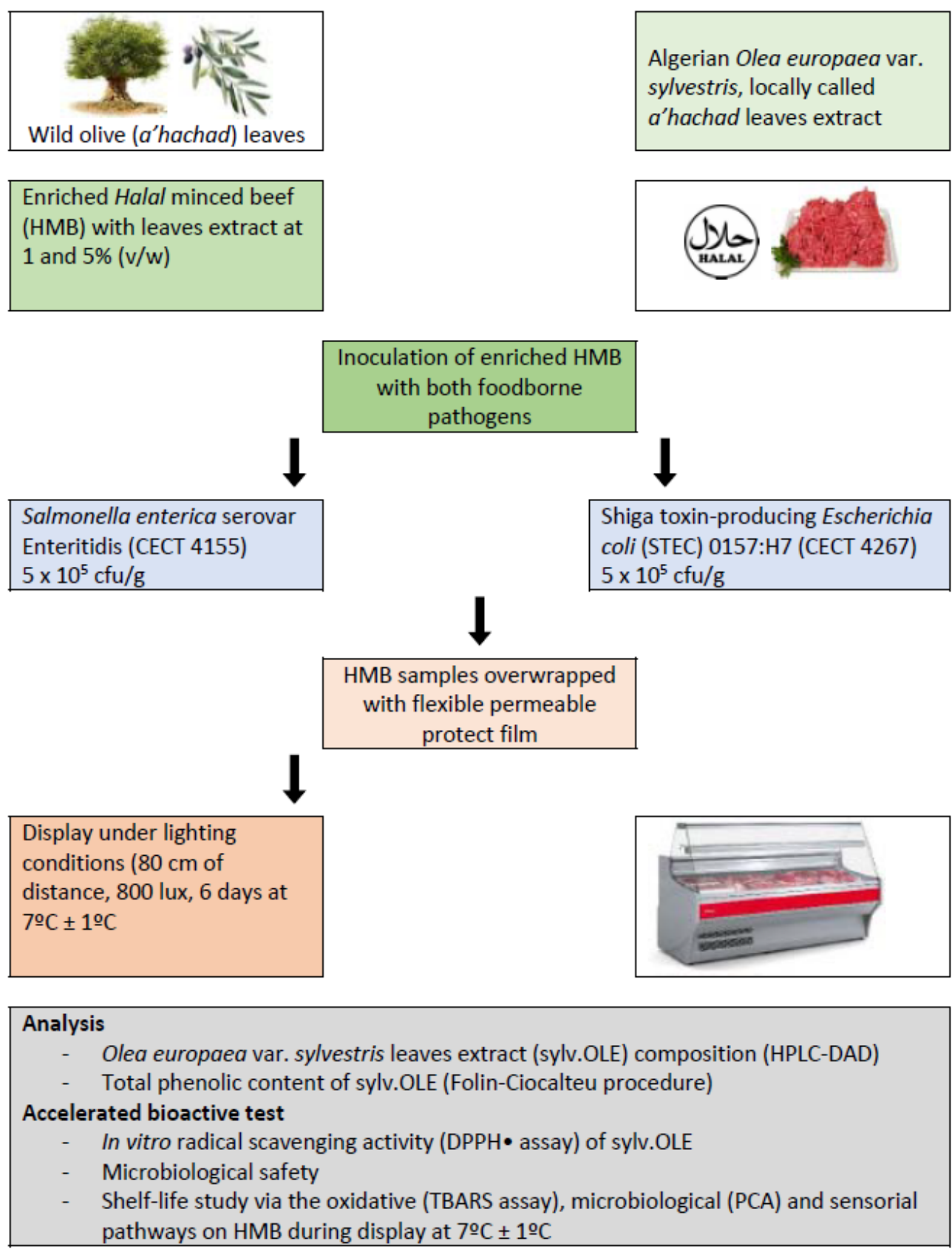

Figure 1. Experimental design: Sylv.OLE (extract from leaves of Algerian oleaster) application in Halal minced beef. HMB: Halal minced beef; STEC: shiga toxin-producing Escherichia coli; CECT: Colección Española de Cultivos Tipo (Spanish Type Culture Collection); HPLC: High Performance Liquid Chromatography; DAD: Diode Array Detector; DPPH•: stable radical 2,2-diphenyl-1-picrylhydrazyl; TBARS: thiobarbituric acid reactive substances; PCA: Plate Count Agar. 


\subsubsection{Microorganisms and Standardization of Inoculum}

The foodborne pathogens used in this work were; S. enterica ser. Enteritidis (CECT 4155) and Shiga toxin-producing Escherichia coli O157:H7 (CECT 4267), which were acquired from Spanish Type Culture Collection (Colección Española de Cultivos Tipo: CECT). To standardize the number of cells, a tube with sterile brain heart infusion (BHI) broth (Oxoid Ltd. Ref: CM0225) was inoculated from each strain by adding a bead from cryovials (Deltalab, Barcelona, Spain: Ref. 409113/6) stock stored at $-80^{\circ} \mathrm{C}$ (Department of Food Safety, Veterinary Faculty of Zaragoza, Spain). After incubating of the tubes at $37^{\circ} \mathrm{C}$ for $12-16 \mathrm{~h}$, their concentrations were measured by spectrophotometry (Spectronic 20, Bausch \& Lomb, Rochester, NY, USA) after carrying the reading at 59\% transmittance by culture combination and sterile BHI. For each tube with the adjusted transmittance, counts were made on agar plates for plate count (PCA) by seeding $1 \mathrm{~mL}$ of the dilutions $-5,-6$, and -7 to verify the veracity of the spectrophotometer readings. The final bacterial loads were $1.8 \times 10^{8} \mathrm{CFU} / \mathrm{mL}$ for S. enterica ser. Enteritidis, and $3.5 \times 10^{8} \mathrm{CFU} / \mathrm{mL}$ for Escherichia coli O157:H7.

\subsubsection{Halal Minced Beef and Treatments}

Raw Halal minced beef samples were purchased on 3 occasions, during the period of December 2010 through September 2012 from different Halal butchers' at Zaragoza city, Spain. Meat samples were aseptically transported under cool conditions $\left(1 \pm 1^{\circ} \mathrm{C}\right)$ to the laboratory of Food safety, Veterinary Faculty of Zaragoza (Spain) within $30 \mathrm{~min}$. The total quantity of minced meat purchased was strictly maintained at $1 \pm 1{ }^{\circ} \mathrm{C}$ and all subsequent preparations were held in a cold room at $2 \pm 1^{\circ} \mathrm{C}$. Samples were divided into various small lots, and were subjected to different treatments. Individual samples of about $100 \mathrm{~g}$ weight were aseptically processed, placed into sterile stomacher bags, and contaminated separately with each pathogen (final concentration: $\sim 5.0 \times 10^{5} \mathrm{CFU} / \mathrm{g}$ ). In order to ensure proper distribution of the microorganisms, the inoculated samples were homogenized in the stomacher (400 circulator, Seward) for $2 \mathrm{~min}$. Following homogenization, sylv.OLE was added to the inoculated samples. The following treatments of inoculated minced meat samples were used: Untreated (control), and addition of sylv.OLE ( 1 and $5 \%, \mathrm{v} / \mathrm{w}$ ). To ensure uniform distribution of the added compounds, treated meat samples were further homogenized in the stomacher as previously described. The stomacher bags with samples from all treatments were sealed and placed into polystyrene trays of size $15.5 \times 21.5 \times 2.5 \mathrm{~cm}$. All trays were stored in refrigerated cabinets under illumination at $\sim 7 \pm 1{ }^{\circ} \mathrm{C}$ for 6 days, simulating proper refrigeration retail/display. The initial microbiological quality was also determined in purchased HMB prior to laboratory studies. Three samples from each group were taken at each selected time $(0,2,4$, and 6 days) for subsequent analysis.

\subsubsection{Microbiological Analysis}

For the enumeration of Salmonella enterica ser. Enteritidis, $25 \mathrm{~g}$ of HMB were added in duplicate to $100 \mathrm{~mL}$ of buffered peptone water (BPW; Oxoid Ltd. (Hampshire, UK) Ref: CM1049; dilution 1:5) in a sterile plastic stomacher filter bag (Seward). The mixture was homogenized in the stomacher for $1 \mathrm{~min}$, and $0.33 \mathrm{~mL}$ were plated in triplicate onto ChromID ${ }^{\mathrm{TM}}$ Salmonella agar (BioMérieux SA, Marcy l'Etoile, France, Ref: 43621 ), which was incubated at $37^{\circ} \mathrm{C}$ for $18-24 \mathrm{~h}$.

For enumeration of E. coli O157:H7 by direct plating, $25 \mathrm{~g}$ of HMB were weighed in duplicate in a volume of $100 \mathrm{~mL}$ of modified tryptone soya Broth (Oxoid Ltd. Ref: CM0989) + novobiocin (Oxoid Ltd. Ref: SR0181). The mixture was homogenized in the stomacher during $1 \mathrm{~min}$, and $0.33 \mathrm{~mL}$ were plated in triplicate onto ChromID ${ }^{\mathrm{TM}} \mathrm{O} 157: \mathrm{H7}$ agar (BioMérieux SA, Ref: 42605 ), which was incubated at $37^{\circ} \mathrm{C}$ for $18-24 \mathrm{~h}$.

For the enumeration of psychrotrophic bacteria, $25 \mathrm{~g}$ from each individual sample of HMB were taken and diluted in $225 \mathrm{~mL} 0.1 \%$ peptone water (PW). The mixture was homogenized in a stomacher for $1 \mathrm{~min}$. Serial 10-fold dilutions were prepared by diluting $1 \mathrm{~mL}$ in $9 \mathrm{~mL}$ of $0.1 \%$ PW. Three plates were prepared from each dilution by pouring $1 \mathrm{~mL}$ in fluid agar. Counts of aerobic psychrotrophic 
bacteria were determined in plate count agar (PCA; Merck, Darmstadt, Germany) and incubated at $7{ }^{\circ} \mathrm{C}$ for 10 days. Counts were expressed as $\log _{10}$ of colony forming units/g (CFU/g). The logs of mean values for the counts from triplicate plates were recorded.

\subsubsection{Malonaldehyde Compounds as Lipid Oxidation Biomarkers in HMB}

During the display period, the degree of lipid oxidation was determined using 2-thiobarbituric acid (TBA) to measure secondary oxidation products, described by Djenane et al. [17]. The results were expressed as mg malonaldehyde (MDA) $/ \mathrm{kg}$ of product and calculated using a standard curve prepared with 1,1,3,3-tetramethoxypropane (Sigma Aldrich Corporation, St. Louis, MO, USA).

\subsubsection{Sensory Evaluation of Halal Minced Beef}

Only sylv.OLE control samples were subjected to evaluation of their sensory properties, using the method described by the American Meat Science Association guidelines [18]. Eight (08) panelists were selected from laboratory staff (Laboratory of Food Science, University of Zaragoza, Spain). Panelists evaluated the fresh meat "off-odor" referred to the intensity of odors associated to both oxidation and microbiological product spoilage, using a numerical scale of $1-5$ (with $1=$ none and $5=$ extreme), as well as the bitterness by using a numerical scale of $1-5$ (with $1=$ no bitterness and $5=$ very bitter). Finally, panelists evaluated the "overall acceptability" of each sample taking into account any "off-flavor" and undesirable taste, using a numerical scale of $1-5$ (with $1=$ very acceptable and $5=$ unacceptable). For bitterness and overall acceptability evaluation, HMB were cooked for $30 \mathrm{~min}$, and served warm to panelists. Each sample was presented with a three-digit code randomly chosen. A score value higher than 3 of any attribute, denoted that minced beef was not acceptable by panelists probably due to end of shelf-life. Three samples from each group were taken at each selected time $(0,2,4$, and 6 days) for subsequent sensorial analysis.

\subsubsection{Statistical Analysis}

Results were presented as the means of three independent experiments conducted at least in triplicate \pm standard deviation for each experimental design. The data were analyzed by $t$-student's test and ANOVA to check the effects of treatment and time of storage $(0,2,4$, and 6 days) using the Statistical Package for the Social Sciences software (SPSS version 21, IBM Corporation, Armonk, NY, USA). The effect of the sylv.OLE treatment (1-5\%) on HMB quality and microbiological safety was evaluated during display period with a significance level of $p<0.05$.

\section{Results and Discussion}

\subsection{Total Phenolic Contents}

In $1 \mathrm{~g}$ of dry weight of sylv.OLE, $198.7 \pm 3.6 \mathrm{mg}$ gallic acid equivalent was detected by the Folin-Ciocalteu assay (Table 1). These results suggest that the higher levels of antioxidant activity were due to the presence of phenolic components. Phenolic compounds are known to be good natural antioxidants and are widely investigated in many vegetables and medicinal plants [19]. The total phenolic content in our sylv.OLE was in agreement with Altemimi et al. [20], who found values between $147.78 \pm 0.69$ and $190.44 \pm 0.50 \mathrm{mg} / \mathrm{g}$ in Iraqi olive leaves. According to scientific literature, the content of phenolic compounds in olive leaves varies between $2.8-44.3 \mathrm{mg} / \mathrm{g}$ of dry matter [21-23], but it can even exceed $250.2 \mathrm{mg} / \mathrm{g}$ [24]. The variation in the concentration of phenolic compounds in olive leaves indicated in the literature depends on climate and agronomic conditions, olive cultivar, soil composition, the time of collection of leaf samples, and the age of tree. In addition to these variability factors, there are the effects of storage conditions prior to extraction, method of preparation of olive leaves, and the processing techniques. For example, Boscaiu et al. [25] found that the level of phenolic compounds accumulated in plants and stress (biotic and abiotic) were positively correlated, suggesting a role of these secondary metabolites in the defense mechanisms against this phenomena. 
Table 1. Total phenol content and free-radical scavenging activity of leaves extract from Algerian oleaster (O. europaea var. sylvestris).

\begin{tabular}{cllcc}
\hline Method & \multicolumn{1}{c}{ Parameters } & Sylv.OLE & Standard BHT \\
\hline & - & $\mathrm{IC}_{50}(\mu \mathrm{g} / \mathrm{mL})^{2}$ & $19.2 \pm 1.6$ & $11.4 \pm 0.5$ \\
\multirow{2}{*}{ Free-radical scavenging activity ${ }^{1}$} & - & $\mathrm{AAI}^{3}$ & $4.2 \pm 0.1$ & $7.1 \pm 0.2$ \\
& - & Antioxidant activity & Very strong & Very strong \\
Folin-Ciocalteu & - & Phenol content $(\mathrm{mg} / \mathrm{g})$ & $198.7 \pm 3.6$ & \\
\hline
\end{tabular}

${ }^{1} \mathrm{DPPH} \bullet$ scavenging method (mean \pm standard deviation (SD) of three determinations). ${ }^{2} \mathrm{IC}_{50}$ value: Concentration required causing $50 \%$ of DPPH inhibition. A lower $\mathrm{IC}_{50}$ value indicates greater antioxidant activity. ${ }^{3}$ AAI (Antioxidant Activity Index): AAI = DPPH concentration in reaction mixture $(\mu \mathrm{g} / \mathrm{mL}) / \mathrm{IC}_{50}(\mu \mathrm{g} / \mathrm{mL}) ; \mathrm{DPPH}$ concentration in reaction mixture $=80 \mu \mathrm{g} / \mathrm{mL} ; \mathrm{IC}_{50}$ values are defined as the concentration of test material, which is able to decrease the initial concentration of DPPH to half of its initial value; AAI $<0.5$ (Poor); $0.5<\mathrm{AAI}<1.0$ (moderate); $1.0<\mathrm{AAI}<2.0$ (strong), and AAI > 2.0 (very strong). BHT: butylated hydroxytoluene; DPPH $\bullet$ : Stable radical 2,2-diphenyl-1-picrylhydrazyl; Sylv.OLE: extract from leaves of Algerian oleaster.

\subsection{HPLC Analysis}

A chromatographic analysis, by High Performance Liquid Chromatography/Diode Array Detector (HPLC-DAD), was carried out in order to determine the phenolic composition in the sylv.OLE. Ten compounds were identified in this work (Table 2). The quantitative results of the 10 compounds identified showed that the most abundant compound was oleuropein $(43.25 \%)$, as found by various authors [17,26-32]. In addition to oleuropein, other phenolic compounds were identified: verbascoside $(13.12 \%)$, apigenin-7-glucoside $(9.82 \%)$, luteolin-7-glucoside $(1.34 \%)$, hydroxytyrosol $(7.32 \%)$, rutin $(0.76 \%)$, vanillic acid $(0.65 \%)$, luteolin $(0.89 \%)$, tyrosol (3.15\%), and caffeic acid $(0.79 \%)$. The quantitative analysis of our sylv.OLE showed notable differences compared to that obtained from non-sylvester olive leaf extract (OLE) in different regions of the world. Lee-Huang et al. [28] analyzed the OLE and found that this extract contains; oleuropein $(12.8 \%)$, verbascoside $(0.38 \%)$, luteolin-7-glucoside $(0.68 \%)$, rutin $(0.34 \%)$, apigenin-7-glucoside $(0.18 \%)$, and luteolin $(0.41 \%)$. Botsoglou et al. [29] and Hayes et al. [12] quantified various polyphenols in OLE and also reported that oleuropein was the largest fraction present $(43.58 \%)$, while other polyphenols like hydroxytyrosol $(4.56 \%)$, luteolin-7-glucoside $(21.54 \%)$, verbascoside $(25.12 \%)$, tyrosol $(6.58 \%)$, and apigenin-7-O-glucoside $(30.22 \%)$ were also isolated from the leaves. However, Pereira et al. [33] reported that oleuropein and lueolin-7-O-glucoside were the most abundant compounds in a lyophilised OLE. Altiok et al. [21] also quantified oleuropein (29\%) as the major phenolic compounds present in crude OLE. Compared to olive oil and oil mill waste water, olive leaves contain higher oleuropein, which ranges from 1 to $14 \%$ [34,35]. It is well known that the phenolic compositions of olive leaves and subsequent antiradical scavenging are considerably affected by the biological cycle of olive trees, the environmental and agronomical conditions, such as climate, region, and furthermore by point of harvest, ripeness and post-harvest processing, long-term storage stability of dried olive leaves, but also by the methods of sample preparation and extraction and by the method of quantification [36,37].

Many studies have evaluated the therapeutic role of oleuropein and its mechanisms of action. Extensive scientific research has shown that oleuropein has antioxidant [38] and antimicrobial activities [39,40]. The concentration of oleuropein in studied sylv.OLE can reach up to $43 \%$ of dry leaves. As a result, the oleaster is considered a renewable natural source for the extraction of oleuropein. However, to our knowledge, there is little discussion in the literature concerning the possibility to add the sylv.OLE to minced beef in order to increase its shelf-life and for safety considerations. Some works have already demonstrated that biophenols encountered in olive leaves also display a synergistic behavior in their biological activities when used together, showing that the mixture of major and minor bioactive compounds is higher than that of the individual phenolics alone. 
Table 2. Phenolics composition (\%) in Algerian sylv.OLE (extract from leaves of Algerian oleaster).

\begin{tabular}{cc}
\hline Phenol Compounds & Composition (\%) \\
\hline 1. Oleuropein & $43.25 \pm 1.26$ \\
2. Verbascoside & $13.12 \pm 0.96$ \\
3. Apigenin-7-glucoside & $9.82 \pm 1.06$ \\
4. Hydroxytyrosol & $7.32 \pm 0.58$ \\
5. Tyrosol & $3.15 \pm 0.09$ \\
6. Luteolin-7-glucoside & $1.34 \pm 0.08$ \\
7. Luteolin & $0.89 \pm 0.03$ \\
8. Caffeic acid & $0.79 \pm 0.04$ \\
9. Rutin & $0.76 \pm 0.01$ \\
10. Vanillic acid & $0.65 \pm 0.01$ \\
\hline
\end{tabular}

Mean \pm SD (standard deviation) of three determinations by the HPLC-DAD method.

\subsection{In Vitro Antioxidant Activity}

Radical scavenging activity of the sylv.OLE natural product and a synthetic antioxidant butylated hydroxytoluene (BHT) were assessed using the 2,2-diphenyil-picrylhydrazyl (DPPH•) assay (Table 1). The sylv.OLE extracts was more effective in scavenging DPPH ( $\left.\mathrm{IC}_{50}=19.2 \pm 1.6 \mu \mathrm{g} / \mathrm{mL}\right)$ and showed a very strong antioxidant potential with $\mathrm{AAI}=4.2 \pm 0.1$. Although the antioxidant activity found in vitro was only indicative of the potential food benefits, these results remain generally important as the first step in screening the antioxidant activity of sylv.OLE. These extracts owe their antioxidative properties to their high biophenol content, as they possess ideal structural chemistry for free radical scavenging activity. The leaves of sylvester Olea europaea are characterized by high oleuropein content, and also to a lesser amount of hydroxytyrosol. The structure of phenolic compounds is a key determinant of their radical scavenging, and their potential antioxidative activities have been known for a long time. Given sylv.OLE richness in biophenol molecules, this latter may protect the foods from free radical damage. The DPPH radical scavenging potential of olive leaf extract was also investigated by Bouaziz et al. [41], who found an $\mathrm{IC}_{50}=1.5 \mu \mathrm{g} / \mathrm{mL}$ comparable to that of pure oleuropein; $\mathrm{IC}_{50}=1.19 \mu \mathrm{g} / \mathrm{mL}$. The radical scavenging activity of phenolic compounds in sylv.OLE could be due to the presence of the hydroxyl groups in their structure such as oleuropein and hydroxytyrosol. The hydroxytyrosol from OLE has previously shown to have strong DPPH radical scavenging activity [41]. Authors claimed that this biophenol may act as a good hydrogen $(\mathrm{H})$ donator by scavenging free radicals. On the other hand, a good correlation between oleuropein content and antioxidant potency of OLE has been previously reported [42]. For the comparison between total phenolic compounds and scavenging free radical activities, Altemimi et al. [20] found that the plant extracts with the highest amount of phenolic content will be more effective at scavenging free radicals. The sylv.OLE and their biophenol compounds are considered candidate constituents of particular importance. These phytochemical compounds can be studied for their possible promising results with respect to their biological potential activities in the agro-food field. Combinations of OLE biophenol compounds such as hydroxytyrosol with other antioxidants revealed additive effects [43].

A process involving the usage of oleuropein and hydrolysate OLE to produce hydroxytyrosol has been developed by Zafer and Filiz [13], and Bouaziz et al. [41]. These latter found $\mathrm{IC}_{50}=0.58 \mu \mathrm{g} / \mathrm{mL}$ value for OLE hydrolysate, and concluded that this antioxidant power was due to hydroxytyrosol, which resulted from oleuropein hydrolysis. On the other hand, these results can be explained by the phenomena of hydrolysis with the corresponding increase in the antioxidant activity of the extract and probably the synergistic effect between OLE biophenols [13].

\subsection{Microbiological Analysis}

\subsubsection{Plate Count Agar (Psychrotrophic Microbiota)}

The minced meat constitutes, by their intrinsic and extrinsic qualities, are very good substrates for good and fast development of various bacteria. Compared to whole muscle, sometimes, even if 
hygienic conditions and the cold chain are respected, this fragile product may suffer various alterations during storage. Therefore, minimizing product contamination and delaying or inhibiting growth of spoilage and pathogenic organisms in the product are major keys for improving fresh meat shelf-life and increasing consumer safety. Among Muslims, minced meat is almost omnipresent in everyday gastronomic customs, and especially during social and religious events (e.g., marriages, circumcisions, Ramadan, $\mathrm{Al}$ aqîqa, etc.). Often in this community, ground beef is widely consumed in many forms. However, if conditions are favorable for microbial growth, minced beef under various practical meals can deteriorate quickly and can present a health risk to consumers. The total psychrotrophic microbiota is a good indicator for quality control and shelf-life estimation of foodstuffs of animal origin during storage. At high load of psychrotrophic microbiota is synonymous with an imminent microbiological alteration during storage.

Figure 2 shows the evolution of the psychrotrophic microbiota in treated HMB. The addition of extract to the minced meat produced a net regression of the total psychrotrophic microbiota during display period depending on the concentration used. Stronger antimicrobial activity was obtained in the presence of higher concentrations of the extract $(5 \%)$, though, $1 \%$ of the extract also reduced the microbial growth compared to the control $(p<0.05)$. At higher concentrations, the reductions obtained in terms of psychrotrophic microbiota in HMB were 2.31, 2.14, and $2.66 \log _{10} \mathrm{CFU} / \mathrm{g}$ at 2,4 , and 6 days of storage, respectively. From a microbiological point of view, these results have a very positive significance in terms of the microbiological stability and subsequently higher shelf-life of the product during the display period. Indeed, even at the end of the storage period, the level of the microbial load was kept very far from the critical microbiological threshold $\left(\approx 7 \log _{10} \mathrm{CFU} / \mathrm{g}\right.$ $=$ end of shelf-life). However, the control samples began to develop signs of alteration from the 2nd day of storage ( $\left.6.7 \log _{10} \mathrm{CFU} / \mathrm{g}\right)$; on the 4 th day the microbial load already exceeded the critical threshold $\left(7.5 \log _{10} \mathrm{CFU} / \mathrm{g}\right)$. The presence of oleuropein, and to a lesser degree other minor biophenols, in sylv.OLE may partly explain the antimicrobial activity. Juven et al. [44] reported that extracts of green olives exerted an antimicrobial effect against various Gram-positive and Gram-negative bacteria. Likewise, OLE-containing oleuropein and hydroxytyrosol showed important antibacterial effects in raw shrimp by reducing the count of aerobic bacteria by at least $1 \log _{10} \mathrm{CFU} / \mathrm{g}$ compared to the untreated samples [8]. Wei et al. [45] reported that these biophenols exert antimicrobial activity by destroying membrane permeability. Previously, other authors reported that dietary olive leaves were more effective than $\alpha$-tocopheryl acetate supplementation $(p<0.05)$ in inhibiting microbial growth in turkey breast fillets during refrigerated storage [46].

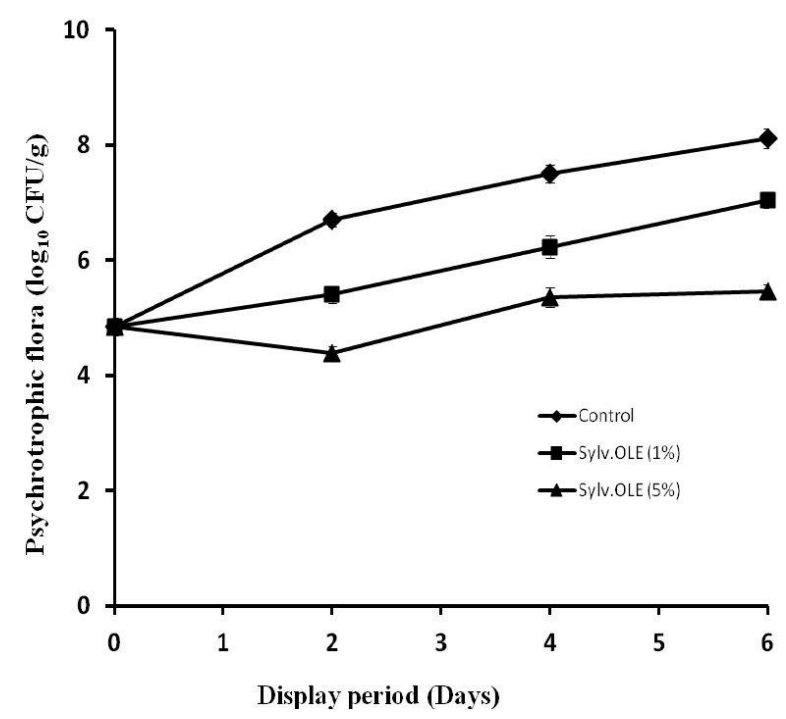

Figure 2. Total psychrotrophic bacteria counts $\left(\log _{10} \mathrm{CFU} / \mathrm{g} \pm \mathrm{SD}\right.$ (standard deviation)) of HMB (Halal minced beef) treated with sylv.OLE during display. 


\subsubsection{Pathogenic Microbiota}

The mincing of meat in butchery Halal at retail/display is a particular critical process, as food borne pathogens will be physically distributed onto various surfaces due to the inadequate temperature control and poor hygiene during mincing operation. This process may lead to spread and growth of pathogens in the product. Therefore, minimizing cross-contamination and delaying growth of food borne pathogens are major keys for increasing consumer safety. There are several studies that have shown a high prevalence of foodborne pathogens in ground meat due the lack of hygiene during the different operations. On the other hand, the consumption of undercooked ground meat is recognized as a major risk factor for people infected by food-borne pathogens. Our research group has postulated the potential use of sylv.OLE for microbial safety of retailed HMB. The results showed that the type of microorganism, the concentration of sylv.OLE additives, and display periods affected the microbiological values $(p<0.05)$. The counts of pathogenic bacteria in minced meat were significantly lower in samples treated with sylv.OLE than in control samples $(p<0.05)$. As shown in Figures 3 and 4 , the growth of both foodborne pathogens increased over display period in control HMB samples without sylv.OLE. The bacterial load reached $\sim 6 \log _{10} \mathrm{CFU} / \mathrm{g}$ for both foodborne pathogens at the end of display. In contrast, the samples treated with $5 \%$ sylv.OLE showed lower counts for both pathogens $(3.85 \pm 0.05$ and $4.15 \pm 0.10 \log 10 \mathrm{CFU} / \mathrm{g}$, respectively for $S$. Enteritidis and E. coli) corresponding to reductions of 1.6 and $1.2 \log 10 \mathrm{CFU} / \mathrm{g}$ as compared with respective initial load.

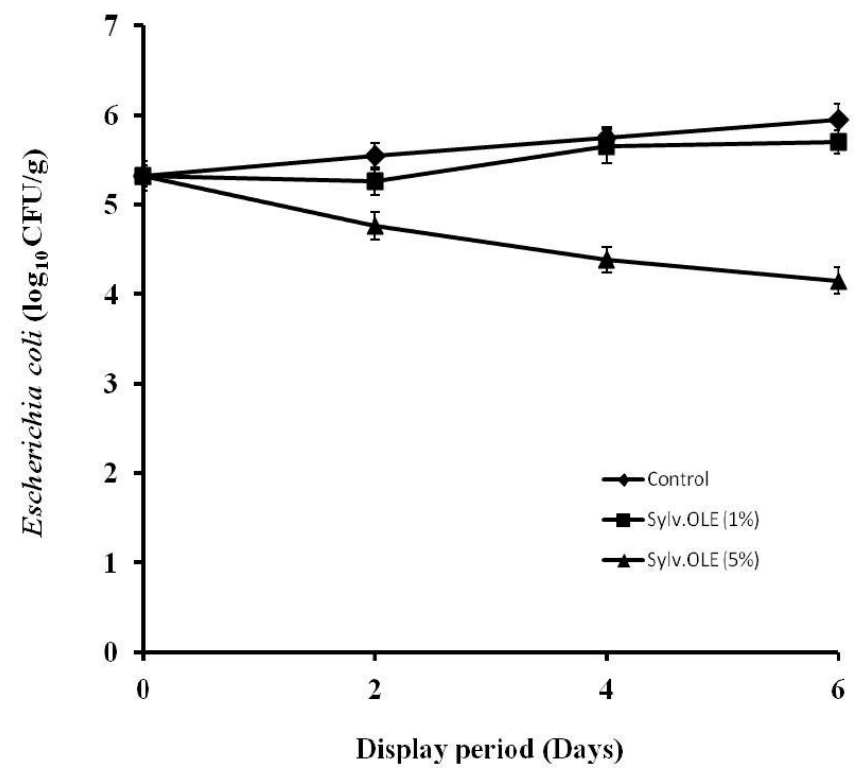

Figure 3. Escherichia coli O157:H7 growth rate in HMB during display in the presence of different sylv.OLE concentrations.

On the other hand, our results revealed that an increase in the concentration of sylv.OLE significantly decreases the bacterial load in inoculated HMB samples $(p<0.05)$. For instance, Salmonella reduction with $1 \%$ sylv.OLE were 0.9 and $1.40 \log 10 \mathrm{CFU} / \mathrm{g}$ on the 4th and 6th day of display, respectively, while $5 \%$ sylv.OLE achieved reductions of 1.38 and $2.15 \log 10$ CFU / g at the same sampling times. Regarding Escherichia coli, there were no statistically significant differences between control samples and those treated with $1 \%$ sylv.OLE $(p>0.05)$. However at $5 \%$ sylv.OLE, reductions of $0.78,1.36$, and $1.80 \log 10 \mathrm{CFU} / \mathrm{g}$ were recorded during the $2 \mathrm{nd}$, 4th, and 6th days of display, respectively. These results were consistent with those of previous works in which olive biophenols showed antimicrobial effects in the food matrix. Medina et al. [47] detected elevated death rates for $S$. Enteritidis in milkor egg-based mayonnaise containing virgin olive oil with high biophenolic content. Hayes et al. [48] studied the antimicrobial effect of OLE on meat and reported a noticeable antimicrobial effect in products under various packaging conditions (MAP and overwrap). Radford et al. [49] conducted a 
study on mayonnaise containing virgin olive oil to determine the antimicrobial effect of OLE. They deduced a good anti-Salmonella Enteritidis activity due mainly to the polyphenol richness of this tested extract.

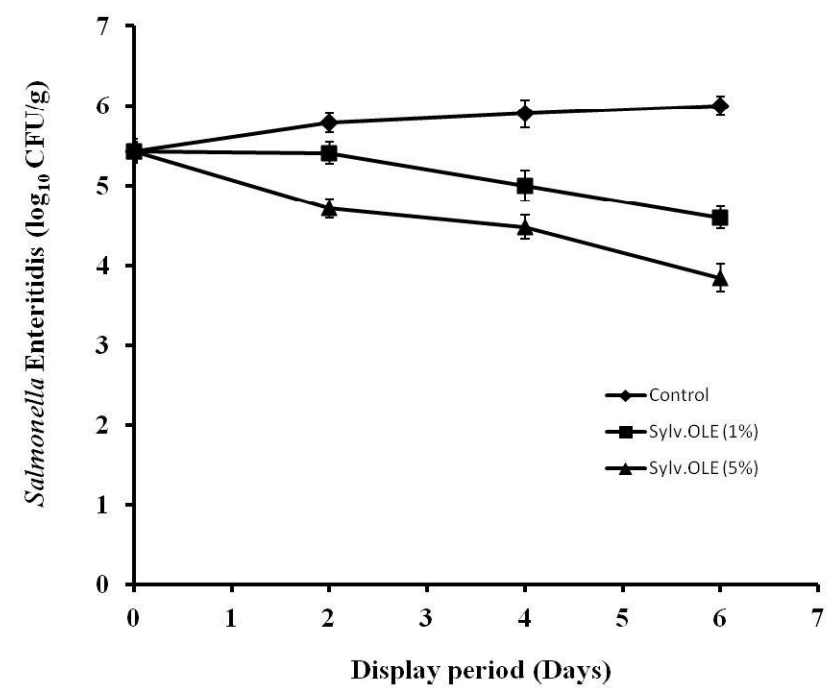

Figure 4. Salmonella enterica ser. Enteritidis growth rate in HMB during display in the presence of different sylv.OLE concentrations.

Antibacterial activity of OLE was also tested using agar dilutions and broth microdilution techniques, and was found to be very active against a wide range of microorganisms, with minimum inhibitory concentrations (MICs) as low as $0.31-0.78 \%$ (v/v) [50]. On the contrary, Albertos et al. [51] found antibacterial activity of OLE against Listeria monocytogenes (L. monocytogenes) in agar diffusion tests, but no effect was observed on S. enterica and E. coli. Campylobacter species were found to be very susceptible in vitro to OLE [50], while Salmonella species were the most resistant [52].

As shown in Tables 1 and 2 sylv.OLE contains high amounts of biophenols (198.7 mg/g). Most of these phenolic compounds have been shown to possess antimicrobial activity. The bactericidal and bacteriostatic activities of oleuropein and hydroxytyrosol have been well investigated [40]. Hydroxytyrosol is the principal product of oleuropein degradation, so its amount in olive leaves increases during several treatments. Koutsoumanis et al. [39] reported that oleuropein exerted a bacteriostatic effect on Salmonella Enteritidis. Further research was conducted regarding the antibacterial effects of oleuropein and some studies have shown rather contradictory results regarding the antimicrobial activity of oleuropein against microorganisms that could be attributed to different methodological approaches. Medina-Martínez et al. [53] recently addressed these discrepancies and re-evaluated the activity against various pathogenic bacteria.

The effect of oleuropein concentration on Staphylococcus aureus (S. aureus) was determined by Tranter et al. [54], who found that at $>0.2 \%(\mathrm{w} / \mathrm{v})$ level, the growth of $S$. aureus and subsequent toxin production were sufficiently delayed, whereas at $0.6 \%$, both metabolic parameters can be completely inhibited. Besides, Tassou and Nychas [55] observed that at reduced pH levels, the antibacterial activity of oleuropein against bacteria was increased. Most studies revealed a higher antimicrobial activity for the oleuropein aglycone compared to the oleuropein glycoside [56]. OLE showed appreciable activity against Campylobacter jejuni (C. jejuni), Helicobacter pylori (H. pylori), and S. aureus, which could indicate the role as potential bioactive compound for the regulation of gastric microbiota [49]. Recent investigations showed the antibacterial potential against L. monocytogenes in cold-smoked salmon packed with plastics films with OLE. Antimicrobial activity of the films was increased with increasing OLE concentration in their formulations. The active films significantly reduced the growth of this pathogen on the product during storage [51]. 
Some information is available regarding the full antimicrobial spectrum of the individual phenolics and their synergisms in combinations, as well as the interactions with food matrix ingredients. Lee and Lee [57] found that $S$. Enteritidis was fully inhibited by the combination of OLE compounds compared to the individual phenolics. Additionally, OLE compounds can be incorporated to foods in microencapsulated forms to enhance activity and preserve sensorial properties.

\subsection{Lipid Oxidation}

Lipid oxidation is the major cause of chemical alteration of animal products during processing and storage [58,59]. The oxidation reactions cause irreversible changes in the taste, flavor, color, and texture of the products, resulting in a decrease in their shelf-life. Synthetic antioxidant substances are often used on a large scale in the food industry to limit this phenomenon. Nevertheless, their use has been questioned by the potential toxicity of these substances. Then, natural antioxidants can constitute a good alternative to protect foods against lipid oxidation. Ground meat, because of its structure, has a much shorter shelf-life than other meats, even when frozen. It is more sensitive to deterioration because the unsaturated fatty acids are distributed evenly throughout the mass, which is exposed to oxygen and light. Spices and herbs are frequently used at Halal butchers during handling and preparation. However, chlorophyll present in these products absorb light and consequently may accelerate the rate of photo-oxidation of minced meat [60]. The antioxidant properties of the sylv.OLE and their capacity to inhibit lipid peroxidation rates in $\mathrm{HMB}$ were characterized in order to make them candidates as substitutes for synthetic antioxidants commonly used to increase the shelf-life of meat products during retail/display in supermarkets.

The thiobarbituric acid reactive substances (TBARS) value of untreated HMB sample without any added sylv.OLE reached a maximum value of $2.42 \mathrm{mg}$ malondialdehyde (MDA) $/ \mathrm{kg}$ after six days of display (Figure 5). On the other hand, our results revealed that an increase in the concentration of sylv.OLE significantly decreases the TBARS value of HMB samples $(p<0.05)$. When measuring TBARS value, lipid oxidation biomarker (malondialdehyde) reacts with thiobarbituric acid. Thus, the rate of reaction increases during meat oxidation. Direct addition of sylv.OLE in HMB had a positive effect on the oxidative stability of product during display times as compared to control (untreated) samples. These results were in agreement with those of previous studies, in which fresh olive leaves or their extracts showed antioxidant effects in the food matrices, such as meat [29,46], in bovine and porcine muscle model systems [48], pork patties during frozen storage [61], and in edible oils [41,62].

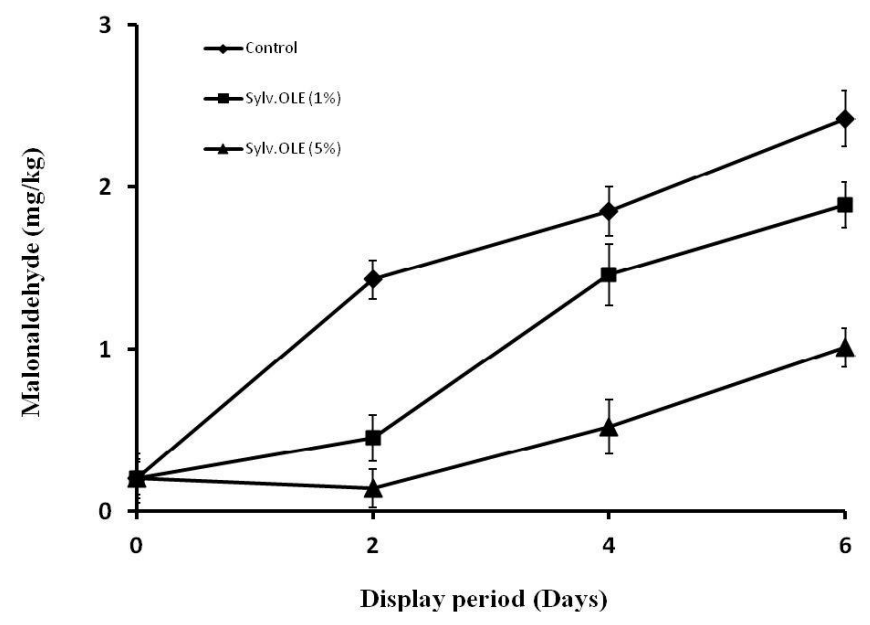

Figure 5. TBARS (thiobarbituric acid reactive substances) values (mg MDA/ $\mathrm{kg}$ ) during display of HMB containing different sylv.OLE concentrations.

Our results showed that both the display period and the concentration of additive affected the TBARS values $(p<0.05)$. The TBARS values of all the tested samples (control and treatment) increased 
constantly with the time of storage. The increase was the most pronounced for the control sample, whose TBARS values rose from $0.2 \mathrm{mg}$ MDA on day 0 , to $2.42 \mathrm{mg}$ at the end of display (6th day). The TBARS value for the treatment with sylv.OLE $1 \%$ at the end of storage was $1.89 \mathrm{mg} \mathrm{MDA} / \mathrm{kg}$, and was significantly lower $(p<0.05)$ than the control. In samples treated with sylv.OLE $5 \%$, the MDA value at day 6 was $1.01 \mathrm{mg}$ MDA $/ \mathrm{kg}$, indicating a significant reduction by $58 \%$ as compared to the control.

It was observed that TBARS values in pre-cooked beef and pork can be reduced by $83 \%$ and $66 \%$, respectively, using waste waters of olive oil pomace. A strong positive synergism between biophenols present in the extract was detected [63]. Hayes et al. [48] studied, on meat, the antioxidant effect of OLE. In comparison to control, the OLE reduced lipid oxidation by $76-84 \%$ under MAP and by $53-78 \%$ under aerobic conditions. Recently, the use of olive leaves for animal feed strategies had a positive effect on lipid oxidation and on the sensory attributes of meats during refrigerated storage $[29,46]$.

\subsection{Sensory Evaluation}

The displayed, untreated HMB shows an increase in lipid oxidation products and consequently, the appearance of rancid odor after only two days of display (Table 3). The results of this study showed a good correlation between TBARS values and sensory analysis. The statistical study of sensory analysis indicated that there were no significant differences between the two addition levels of sylv.OLE ( $1 \%$ and $5 \%)$ during the first four days of display $(p>0.05)$. However, treated samples were significantly different $(p<0.05)$ from the control. The control samples with the highest levels of TBARS and PCA counts were ranked the most rancid by the sensory panel. In addition, the evaluation of the acceptability by the panelists allowed an estimation of the shelf-life of HMB (Table 4). A recent study on the odor perception of beef steaks, according to their state of freshness, related to the off-odors with the evolution of the concentrations and the nature of the lipid oxidation compounds such as malonaldehyde [17]. The study showed that during refrigerated storage under light, beef steaks gradually lost their fresh smell characteristics to acquire rancid notes. The interest of the olive leaves has been mainly correlated with its content in oleuropein. However, this compound may be responsible for the bitter taste of various products [64]. For this, an investigation of the sensory impact of sylv.OLE on minced meat was carried out. The sensory evaluation of the treated HMB showed a decrease in bitterness during display, as samples containing $1 \%$ or $5 \%$ of sylv.OLE extract $(85.94 \mathrm{mg} / \mathrm{g}$ oleuropein) were accepted in terms of less bitterness. Moreover, in the evaluation of overall acceptability, panelists expressed a clear acceptability towards samples treated with 5\% sylv.OLE. Regarding the stability of biophenol compounds in food applications, Zoidou et al. [65] found that the incorporation of olive biophenol into crude and fermented animal products was not affected during heat treatment. On the other hand, the trend to use plant extracts in foods as natural preservatives, may also influence health of consumers [66].

Table 3. Sensory scores* of treated and untreated Halal minced beef (HMB) during period of display.

\begin{tabular}{cccccc}
\hline \multirow{2}{*}{ Parameters } & Treatments & \multicolumn{4}{c}{ Days of Display } \\
\cline { 2 - 6 } & & $\mathbf{0}$ & $\mathbf{2}$ & $\mathbf{4}$ & $\mathbf{6}$ \\
\hline \multirow{3}{*}{ Bitterness } & Control & $1.00(0.00)$ & $1.00(0.00)$ & $1.00(0.00)$ & $1.00(0.00)$ \\
& HMB (1\%) & $1.88(0.35)$ & $1.75(0.46)$ & $1.63(0.52)$ & $1.75(0.46)$ \\
& HMB (5\%) & $2.63(0.52)$ & $2.63(0.52)$ & $2.38(0.52)$ & $2.00(0.53)$ \\
\hline \multirow{3}{*}{ Off-odor } & Control & $1.00(0.00)$ & $2.63(0.52)$ & $3.25(0.46)$ & $4.00(0.53)$ \\
& HMB (1\%) & $1.00(0.00)$ & $2.38(0.52)$ & $2.63(0.52)$ & $3.13(0.35)$ \\
& HMB (5\%) & $1.00(0.00)$ & $2.13(0.35)$ & $2.25(0.46)$ & $2.25(0.46)$ \\
\hline \multirow{2}{*}{ Overall } & Control & $1.00(0.00)$ & $2.63(0.52)$ & $3.38(0.52)$ & $4.25(0.46)$ \\
acceptability & HMB (1\%) & $1.00(0.00)$ & $2.00(0.53)$ & $2.63(0.52)$ & $3.63(0.52)$ \\
& HMB (5\%) & $1.25(0.46)$ & $2.00(0.53)$ & $2.38(0.52)$ & $2.50(0.53)$ \\
\hline
\end{tabular}

Values represent the scale of studied parameters (1-5) and the mean and standard deviation (in parenthesis) of eight observations. *A score value $\geq 3$ of any attribute, denoted that minced beef was not acceptable by panelists due to the end of the shelf-life. HMB (1\%): Halal minced beef treated with sylv.OLE at $1 \%$. HMB (5\%): Halal minced beef treated with sylv.OLE at $5 \%$. 
Table 4. Shelf-life (days) determination.

\begin{tabular}{cc}
\hline Sample Type & Shelf-Life Period (days) at $7{ }^{\circ} \mathbf{C}$ \\
\hline Control & 2 \\
Sylv.OLE $(1 \%)$ & 4 \\
Sylv.OLE $(5 \%)$ & $>6$ \\
\hline
\end{tabular}

* Shelf-life $=$ the period during which the product is in satisfactory quality state. It is determined based on sensory analysis (attribute scoring: A score $\geq 3$ in any of the parameters denoted that meat was unacceptable for sale or consumption), chemical (thiobarbituric acid reactive substances (TBARS) value: Limit $1.5 \mathrm{mg} \mathrm{MDA} / \mathrm{kg}$ ) and microbiological (Psychrotrophic aerobic count: Limit $7 \log _{10}$ CFU/g) criterion.

\section{Conclusions}

Oleaster leaves, an abundant and low cost raw material, are by-products of the traditional Algerian olive oil extraction process with high potential added value. Large amounts of oleaster leaves are collected during the admission to the oil mill at the first processing stage. The total phenolic compounds content in oleaster leaves extract was $198.7 \mathrm{mg}$ gallic acid equivalents (GAE), and ten compounds were identified of which oleuropein $(43 \%)$, verbascoside $(13 \%)$, apigenin-7-glucoside $(10 \%)$, and hydroxytyrosol $(7 \%)$ were the most abundant.

Our results showed for the first time that the leaves from oleaster are a great source of biophenols, which could be used as natural bioactive compounds in food applications. Halal minced beef (HMB), commonly used for various practical meals by Muslim communities living in Spain, was supplemented with oleaster leaves extract (sylv.OLE) at two levels $(1 \%$ and $5 \%, \mathrm{v} / \mathrm{w})$, and tested for improved microbiological safety and shelf-life during retail display at $7{ }^{\circ} \mathrm{C}$ for six days. Our results of higher levels of antioxidant and antimicrobial activities in supplemented HMB, suggest that the presence of bioactive compounds in oleaster leaves extract was very effective.

Additionally, it has been shown that the presence of this extract at the indicated addition levels did not have a negative influence either on the overall acceptability and bitter taste of treated HMB. However, there is a need for further studies regarding the synergistic behavior with other antimicrobial compounds, such as nisin, and for the application by active packaging techniques in order to produce optimized effects.

Author Contributions: D.D. contributed to: Laboratory work design, analysis and interpretation of data, and drafting of the manuscript. D.G. and J.Y. contributed to: Laboratory work design. P.R. and A.A. contributed to: Manuscript revision and recommendations.

Funding: The present research was carried out with the financial support of the Spanish PCI/MED Grant ALI A/033506/10 PROJECT. Thanks to the Grupo de Investigación A06_17R (Gobierno de Aragón-FEDER, Spain) for financial support.

Conflicts of Interest: The authors declare no conflicts of interest.

\section{References}

1. European Food Safety Authority (EFSA). Panel on biological hazards (BIOHAZ) scientific opinion on the public health risks related to the maintenance of the cold chain during storage and transport of meat. Part 2 (minced meat from all species). EFSA J. 2014, 12, 3783. [CrossRef]

2. Abaza, L.; Taamalli, A.; Nsir, H.; Zarrouk, M. Olive tree (Olea europaea L.) leaves: Importance and advances in the analysis of phenolic compounds: Review. Antioxidants 2015, 4, 682-698. [CrossRef] [PubMed]

3. Carrera-Gonzalez, M.P.; Ramírez-Exposito, M.J.; Mayas, M.D.; Martínez-Martos, J.M. Protective role of oleuropein and its metabolite hydroxytyrosol on cancer. Trends Food Sci. Technol. 2013, 31, 92-99. [CrossRef]

4. Navarro, M.; Morales, F.J. Evaluation of an olive leaf extract as a natural source of antiglycative compounds. Food Res. Int. 2017, 92, 56-63. [CrossRef] [PubMed]

5. Martínez, L.; Ros, G.; Nieto, G. Hydroxytyrosol: Health benefits and use as functional ingredient in meat: Review. Medicines 2018, 5, 13. [CrossRef] [PubMed]

6. Lalas, S.; Athanasiadis, V.; Gortzi, O.; Bounitsi, M.; Giovanoudis, I.; Tsaknis, J.; Bogiatzis, F. Enrichment of table olives with polyphenols extracted from olive leaves. Food Chem. 2011, 127, 1521-1525. [CrossRef] 
7. Goldsmith, C.D.; Vuong, Q.V.; Stathopoulos, C.E.; Roach, P.D.; Scarlett, C.J. Optimization of the aqueous extraction of phenolic compounds from olive leaves. Antioxidants 2014, 3, 700-712. [CrossRef]

8. Ahmed, A.M.; Rabii, N.S.; Garbaj, A.M.; Abolghait, S.K. Antibacterial effect of olive (Olea europaea L.) leaves extract in raw peeled undeveined shrimp (Penaeus semisulcatus). Int. J. Vet. Sci. Med. 2014, 2, 53-56. [CrossRef]

9. Romani, A.; Pinelli, P.; Ieri, F.; Bernini, R. Sustainability, innovation, and green chemistry in the production and valorization of phenolic extracts from Olea europaea L. Sustainability 2016, 8, 1002. [CrossRef]

10. Berbel, J.; Posadillo, A. Review and analysis of alternatives for the valorisation of agro-industrial olive oil by-products. Sustainability 2018, 10, 237. [CrossRef]

11. Nunes, M.A.; Pimentel, F.B.; Costa, A.S.G.; Alves, R.C.; Oliveira, M.B.P.P. Olive by-products for functional and food applications: Challenging opportunities to face environmental constraints. Innov. Food Sci. Emerg. Technol. 2016, 35, 139-148. [CrossRef]

12. Hayes, J.E.; Allen, P.; Brunton, N.; O'Grady, M.N.; Kerry, J.P. Phenolic composition and in vitro antioxidant capacity of four commercial phytochemical products: Olive leaf extract (Olea europaea L.), lutein, sesamol and ellagic acid. Food Chem. 2011, 126, 948-955. [CrossRef]

13. Erbay, Z.; Icier, F. The importance and potential uses of olive leaves. Food Rev. Int. 2010, 26, 319-334. [CrossRef]

14. Singleton, V.L.; Orthofer, R.; Lamuela-Raventós, R.M. Analysis of total phenols and other oxidation substrates and antioxidants by means of Folin-Ciocalteu reagent. Methods Enzymol. 1999, 299, 152-178.

15. Taoudiat, A.; Djenane, D.; Ferhat, Z.; Spigno, G. The effect of Laurus nobilis L. essential oil and different packaging systems on the photo-oxidative stability of Chemlal extra-virgin olive oil. J. Food Sci. Technol. 2018, 55, 4212-4222. [CrossRef] [PubMed]

16. Scherer, R.; Godoy, H.T. Antioxidant activity index (AAI) by the 2,2-diphenyl-1-picrylhydrazyl method. Food Chem. 2009, 112, 654-658. [CrossRef]

17. Djenane, D.; Beltrán, J.A.; Camo, J.; Roncalés, P. Influence of vacuum ageing times of whole beef on retail shelf-life of steaks packaged with oregano (Origanum vulgare L.) active film under high $\mathrm{O}_{2}$. J. Food Sci. Technol. 2016, 53, 4244-4257. [CrossRef] [PubMed]

18. AMSA. Research Guidelines for Cookery, Sensory Evaluation, and Instrumental Tenderness Measurements of Fresh Meat; American Meat Science Association and the National Livestock and Meat Board: Chicago, IL, USA, 1995.

19. Ben Miri, Y.; Ariño, A.; Djenane, D. Study of antifungal, anti-aflatoxigenic, antioxidant activity and phytotoxicity of Algerian Citrus limon var. Eureka and Citrus sinensis var. Valencia essential oils. J. Essent. Oil Bear. Plants 2018, 21, 345-361. [CrossRef]

20. Altemimi, A.B. A study of the protective properties of Iraqi olive leaves against oxidation and pathogenic bacteria in food applications. Antioxidants 2017, 6, 34. [CrossRef]

21. Altıok, E.; Bayçin, D.; Bayraktar, O.; Ülkü, S. Isolation of polyphenols from the extracts of olive leaves (Olea europaea L.) by adsorption on silk fibroin. Sep. Purif. Technol. 2008, 62, 342-348. [CrossRef]

22. Boudhrioua, N.; Bahloul, N.; Ben Slimen, I.; Kechaou, N. Comparison on the total phenol contents and the color of fresh and infrared dried olive leaves. Ind. Crops Prod. 2009, 29, 412-419. [CrossRef]

23. Lafka, I.T.; Lazou, E.A.; Sinanoglou, J.V.; Lazos, E. Phenolic extracts from wild olive leaves and their potential as edible oils antioxidants. Foods 2013, 2, 18-31. [CrossRef] [PubMed]

24. Mylonaki, S.; Kiassos, E.; Makris, D.; Kefalas, P. Optimisation of the extraction of olive (Olea europaea) leaf phenolics using water/ethanol-based solvent systems and response surface methodology. Anal. Bioanal. Chem. 2008, 392, 977-998. [CrossRef] [PubMed]

25. Boscaiu, M.; Sánchez, M.; Bautista, I.; Donat, P.; Lidón, A.; Llinares, J.; Llul, C.; Mayoral, O.; Vicente, O. Phenolic compounds as stress markers in plants from Gypsum habitats. Bull. UASVM Hortic. 2010, 67, 1843-5254.

26. Benavente-Garcia, O.; Castillo, J.; Lorente, J.; Ortuño, A.; Del Rio, J.A. Antioxidant activity of phenolics extracted from Olea europaea L. leaves. Food Chem. 2000, 68, 457-462. [CrossRef]

27. Lee, O.H.; Lee, B.Y.; Lee, J.; Lee, H.B.; Son, J.Y.; Park, C.S.; Shetty, K.; Kim, Y.C. Assessment of phenolics-enriched extract and fractions of olive leaves and their antioxidant activities. Bioresour. Technol. 2009, 100, 6107-6113. [CrossRef] [PubMed] 
28. Lee-Huang, S.; Zhang, L.; Lin Huang, P.; Chang, Y.-T.; Huang, P.L. Anti-HIV activity of olive leaf extract (OLE) and modulation of host cell gene expression by HIV-1infection and OLE treatment. Biochem. Biophys. Res. Commun. 2003, 307, 1029-1037. [CrossRef]

29. Botsoglou, E.; Govaris, A.; Fletouris, D.; Botsoglou, N. Lipid oxidation of stored eggs enriched with very long chain $n$-3 fatty acids, as affected by dietary olive leaves (Olea europaea L.) or a-tocopheryl acetate supplementation. Food Chem. 2012, 134, 1059-1068. [CrossRef] [PubMed]

30. Herrero, M.; Temirzoda, T.N.; Segura-Carretero, A.; Quirantes, R.; Plaza, M.; Ibañez, E. New possibilities for the valorization of olive oil by-products. J. Chromatogr. A 2011, 1218, 7511-7520. [CrossRef] [PubMed]

31. Guinda, A.; Castellano, J.M.; Santos-Lozano, J.M.; Delgado-Hervás, T.; Gutiérrez-Adánez, P.; Rada, M. Determination of major bioactive compounds from olive leaf. LWT-Food Sci. Technol. 2015, 64, 431-438. [CrossRef]

32. Talhaoui, N.; Vezza, T.; Gómez-Caravaca, A.M.; Fernández-Gutiérrez, A.; Gálvez, J.; Segura-Carretero, A. Phenolic compounds and in vitro immunomodulatory properties of three Andalusian olive leaf extracts. J. Funct. Foods 2016, 22, 270-277. [CrossRef]

33. Pereira, A.P.; Ferreira, I.C.F.R.; Marcelino, F.; Valentão, P.; Andrade, P.B.; Seabra, R.; Estevinho, L.; Bento, A.; Pereira, J.A. Phenolic compounds and antimicrobial activity of olive (Olea europaea L. Cv. Cobrançosa) leaves. Molecules 2007, 12, 1153-1162. [CrossRef] [PubMed]

34. Japón-Luján, R.; Luque de Castro, M.D. Superheated liquid extraction of oleuropein and related biophenols from olive leaves. J. Chromatogr. A 2006, 1136, 185-191. [CrossRef] [PubMed]

35. Japón-Luján, R.; Luque-Rodríguez, J.M.; Luque de Castro, M.D. Dynamic ultrasound-assisted extraction of oleuropein and related biophenols from olive leaves. J. Chromatogr. A 2006, 1108, 76-82. [CrossRef] [PubMed]

36. Ahmad-Qasem, M.H.; Ahmad-Qasem, B.H.; Barrajón-Catalán, E.; Micol, V.; Cárcel, J.A.; García-Pérez, J.V. Drying and storage of olive leaf extracts. Influence on polyphenols stability. Ind. Crops Prod. 2016, 79, 232-239. [CrossRef]

37. Brahmi, F.; Mechri, B.; Dhibi, M.; Hammami, M. Variations in phenolic compounds and antiradical scavenging activity of Olea europaea leaves and fruits extracts collected in two different seasons. Ind. Crops Prod. 2013, 49, 256-264. [CrossRef]

38. Yoon, S.K. Book Chapter: Oxidative Stress and Dietary Antioxidants-The Liver; Chapter 27-Oleuropein as an Antioxidant and Liver Protect; Patel, V.B., Rajendram, R., Preedy, V.R., Eds.; Elsevier Inc.: Amsterdam, The Netherlands, 2018; pp. 323-335. ISBN 978-0-12-803951-9.

39. Koutsoumanis, K.; Tassou, C.C.; Taoukis, P.S.; Nychas, G.-J.E. Modelling the effectiveness of a natural antimicrobial on Salmonella Enteritidis as a function of concentration, temperature and $\mathrm{pH}$, using conductance measurements. J. Appl. Microbiol. 1998, 84, 981-987. [CrossRef] [PubMed]

40. Soler-Rivas, C.; Espín, J.C.; Wichers, H.J. An easy and fast test to compare total free radical scavenger capacity of foodstuffs. Phytochem. Anal. 2000, 11, 330-338. [CrossRef]

41. Bouaziz, M.; Fki, I.; Jemai, H.; Ayadi, M.; Sayadi, S. Effect of storage on refined and husk olive oils composition: Stabilization by addition of natural antioxidants from Chemlali olive leaves. Food Chem. 2008, 108, 253-262. [CrossRef]

42. Conde, E.; Cara, C.; Moure, A.; Ruiz, E.; Castro, E.; Domínguez, H. Antioxidant activity of the phenolic compounds released by hydrothermal treatments of olive tree pruning. Food Chem. 2008, 114, 806-812. [CrossRef]

43. Tafesh, A.; Najami, N.; Jadoun, J.; Halahlih, F.; Riepl, H.; Azaizeh, H. Synergistic antibacterial effects of polyphenolic compounds from olive mill wastewater. Evid. Based Complement. Altern. Med. 2011, 2011, 431021. [CrossRef] [PubMed]

44. Juven, B.; Henis, Y.; Jacoby, B. Studies on the mechanism of the antimicrobial action of oleuropein. J. Appl. Microbiol. 1972, 35, 559-567. [CrossRef]

45. Wei, J.; Wang, S.; Pei, D.; Qu, L.; Li, Y.; Chen, J.; Di, D.; Gao, K. Antibacterial activity of hydroxytyrosol acetate from olive leaves (Olea Europaea L.). Nat. Prod. Res. 2018, 32, 1967-1970. [CrossRef] [PubMed]

46. Botsoglou, E.; Govaris, A.; Christaki, E.; Botsoglou, N. Effect of dietary olive leaves and/or $\alpha$-tocopheryl acetate supplementation on microbial growth and lipid oxidation of turkey breast fillets during refrigerated storage. Food Chem. 2010, 121, 17-22. [CrossRef]

47. Medina, E.; Romero, C.; Brenes, M.; de Castro, A. Antimicrobial activity of olive Oil, vinegar, and various beverages against foodborne pathogens. J. Food Prot. 2007, 70, 1194-1199. [CrossRef] 
48. Hayes, J.E.; Stepanyan, V.; Allen, P.; O'Grady, M.N.; O’Brien, N.M.; Kerry, J.P. The effect of lutein, sesamol, ellagic acid and olive leaf extract on lipid oxidation and oxymyoglobin oxidation in bovine and porcine muscle model Systems. Meat Sci. 2009, 83, 201-208. [CrossRef]

49. Radford, S.A.; Tassou, C.C.; Nychas, G.J.E.; Board, R.G. The influence of different oils on the death rate of Salmonella Enteritidis in homemade mayonnaise. Lett. Appl. Microbiol. 1991, 12, 125-128. [CrossRef]

50. Sudjana, A.N.; D’Orazio, C.; Ryan, V.; Rasool, N.; Islam, N.; Ng, J.; Riley, T.V.; Hammer, K.A. Antimicrobial activity of commercial Olea europaea (olive) leaf extract. Int. J. Antimicrob. Agents 2009, 33, 461-463. [CrossRef]

51. Albertos, I.; Avena-Bustillos, R.J.; Martín-Diana, A.B.; Du, W.X.; Rico, D.; McHugh, T.H. Antimicrobial olive leaf gelatin films for enhancing the quality of cold smoked salmon. Food Packag. Shelf Life 2017, 13, 49-55. [CrossRef]

52. Korukluoglu, M.; Sahan, Y.; Yigit, A.; Tumay Ozer, E.; Gücer, S. Antibacterial activity and chemical constitutions of Olea europaea L. leaf extracts. J. Food Process. Preserv. 2010, 34, 383-396. [CrossRef]

53. Medina-Martínez, M.S.; Truchado, P.; Castro-Ibáñez, I.; Allende, A. Antimicrobial activity of hydroxytyrosol: A current controversy. Biosci. Biotechnol. Biochem. 2016, 80, 801-810. [CrossRef] [PubMed]

54. Tranter, H.S.; Tassou, C.C.; Nychas, G.J.E. Effect of the olive phenolic compound, oleuropein on enterotoxin B production by Staphylococcus aureus S-6. J. Appl. Bacteriol. 1993, 74, 253-260. [CrossRef] [PubMed]

55. Tassou, C.C.; Nychas, G.J.E. Inhibition of Salmonella Enteritidis by oleuropein in broth and in a model food system. Lett. Appl. Microbiol. 1995, 20, 120-124. [CrossRef] [PubMed]

56. Fleming, H.P.; Walter, W.M., Jr.; Etchells, J.L. Antimicrobial properties of oleuropein and products of its hydrolysis from green olives. Appl. Microbiol. 1973, 26, 777-782. [PubMed]

57. Lee, O.H.; Lee, B.Y. Antioxidant and antimicrobial activities of individual and combined phenolics in Olea europaea leaf extract. Bioresour. Technol. 2010, 101, 3751-3754. [CrossRef]

58. Djenane, D. Chemical profile, antibacterial and antioxidant activity of Algerian citrus essential oils and their application in Sardina pilchardus. Foods 2015, 4, 208-228. [CrossRef] [PubMed]

59. Djenane, D.; Roncalés, P. Carbon monoxide in meat and fish packaging: Advantages and limits. Foods 2018, 7, 12. [CrossRef] [PubMed]

60. Choe, E.; Min, D.B. Mechanisms of antioxidants in the oxidation of foods. Compr. Rev. Food Sci. Food Saf. 2009, 8, 345-358. [CrossRef]

61. Botsoglou, E.; Govaris, A.; Ambrosiadis, I.; Fletouris, D.; Botsoglou, N. Effect of olive leaf (Olea europea L.) extracts on protein and lipid oxidation of long-term frozen n-3 fatty acids-enriched pork patties. Meat Sci. 2014, 98, 150-157. [CrossRef]

62. Kiritsakis, K.; Kontominas, M.G.; Kontogiorgis, C.; Hadjipavlou-Litina, D.; Moustakas, A.; Kiritsakis, A. Composition and antioxidant activity of olive leaf extracts from Greek olive cultivars. J. Am. Oil Chem. Soc. 2010, 87, 369-376. [CrossRef]

63. DeJong, S.; Lanari, M.C. Extracts of olive polyphenols improve lipid stability in cooked beef and pork: Contribution of individual phenolics to the antioxidant activity of the extract. Food Chem. 2009, 116, 892-897. [CrossRef]

64. Bianchi, G. Review Article: Lipids and phenols in table olives. Eur. J. Lipid Sci. Technol. 2003, 105, $229-242$. [CrossRef]

65. Zoidou, E.; Magiatis, P.; Melliou, E.; Constantinou, M.; Haroutounian, S.; Skaltsounis, A.L. Oleuropein as a bioactive constituent added in milk and yogurt. Food Chem. 2014, 158, 319-324. [CrossRef] [PubMed]

66. European Food Safety Authority (EFSA). Opinion: Guidance on safety assessment of botanicals and botanical preparations intended for use as ingredients in food supplements. EFSA J. 2009, 7, 1249.

(C) 2018 by the authors. Licensee MDPI, Basel, Switzerland. This article is an open access article distributed under the terms and conditions of the Creative Commons Attribution (CC BY) license (http://creativecommons.org/licenses/by/4.0/). 